\title{
Recurrent Mossy Fibers Establish Aberrant Kainate Receptor-Operated Synapses on Granule Cells from Epileptic Rats
}

\author{
Jérôme Epsztein, Alfonso Represa, Isabel Jorquera, Yehezkel Ben-Ari, and Valérie Crépel \\ Institut de Neurobiologie de la Méditerranée, Institut National de la Santé et de la Recherche Médicale, Unité 29, and Université de la Méditerranée, Parc \\ Scientifique de Luminy, 13273 Marseille Cedex 09, France
}

\begin{abstract}
Glutamatergic mossy fibers of the hippocampus sprout in temporal lobe epilepsy and establish aberrant synapses on granule cells from which they originate. There is currently no evidence for the activation of kainate receptors (KARs) at recurrent mossy fiber synapses in epileptic animals, despite their important role at control mossy fiber synapses. We report that KARs are involved in ongoing glutamatergic transmission in granule cells from chronic epileptic but not control animals. KARs provide a substantial component of glutamatergic activity, because they support half of the non-NMDA receptor-mediated excitatory drive in these cells. KAR-mediated EPSC $\mathrm{KA}_{\mathrm{A}}$ are selectively generated by recurrent mossy fiber inputs and have a slower kinetics than $\mathrm{EPSC}_{\mathrm{AMPA}}$. Therefore, in addition to axonal rewiring, sprouting of mossy fibers induces a shift in the nature of glutamatergic transmission in granule cells that may contribute to the physiopathology of the dentate gyrus in epileptic animals.
\end{abstract}

Key words: kainate receptors; mossy fibers; granule cells; hippocampus; epilepsy; kainic acid

\section{Introduction}

In both human patients and animal models of temporal lobe epilepsy (TLE), glutamatergic fibers sprout and establish novel synapses that lead to an enhanced glutamatergic excitatory drive, which may contribute to seizure generation (Ben-Ari and Represa, 1990; Nadler, 2003). Glutamate acts on three main types of ionotropic receptors: AMPA receptors (AMPARs), NMDA receptors (NMDARs), and kainate receptors (KARs) receptors. Classically, the activation of AMPA receptors is responsible for most of the glutamatergic excitatory drive on central neurons. However, recent studies indicate that KAR-operated synapses play a more important role than initially thought in glutamatergic transmission (Castillo et al., 1997; Vignes and Collingridge, 1997; Cossart et al., 1998; Frerking et al., 1998; Li and Rogawski, 1998; DeVries and Schwartz, 1999; Li et al., 1999). Despite this important role, it is not known whether glutamatergic fibers establish KAR-operated synapses after sprouting to aberrant targets in chronic epileptic rats. Sprouting of mossy fibers is one of the best-documented examples of seizure-triggered reactive plasticity in human patients and animal models of TLE (Represa et al., 1989, 1993; Sutula et al., 1989; Isokawa et al., 1993; Mello et al., 1993; Franck et al., 1995; Okazaki et al., 1995; Buckmaster and Dudek, 1999). This sprouting leads to the formation of a func-

\footnotetext{
Received April 14, 2005; revised July 14, 2005; accepted July 19, 2005.

This work was supported by the Institut National de la Santé et de la Recherche Médicale. We thank Dr. R. Cossart for helpful comments and Dr. M. Esclapez for help with the pilocarpine-treated rats. J.E. is a fellow of the French "Ministère de la Recherche" and was supported by the Fondation pour la Recherche Médicale.

Correspondence should be addressed to Valérie Crépel, Institut de Neurobiologie de la Méditerranée, Parc Scien-

tifique de Luminy, Boîte Postale 13, 13273 Marseille Cedex 9, France. E-mail: crepel@inmed.univ-mrs.fr. DOI:10.1523/JNEUROSCI.1469-05.2005

Copyright $\odot 2005$ Society for Neuroscience $\quad 0270-6474 / 05 / 258229-11 \$ 15.00 / 0$
}

tional recurrent excitatory circuit between granule cells (GCs) (Tauck and Nadler, 1985; Wuarin and Dudek, 1996; Molnar and Nadler, 1999; Lynch and Sutula, 2000; Buckmaster et al., 2002; Scharfman et al., 2003), which accounts for, in part, the enhanced ability of the hippocampus to generate epileptiform activities in hippocampal slices from animal models and from patients with TLE (Patrylo and Dudek, 1998; Hardison et al., 2000; Gabriel et al., 2004).

In the control hippocampus, several observations have shown that KAR-mediated synaptic transmission is strongly associated to the presence of mossy fiber terminals: (1) the stratum lucidum (the target zone of mossy fibers on CA3 pyramidal neurons) contains among the highest density of KARs in the brain (Monaghan and Cotman, 1982); (2) the stimulation of mossy fibers selectively generate $\mathrm{EPSC}_{\mathrm{KA}}$ in CA3 pyramidal cells (Castillo et al., 1997; Vignes and Collingridge, 1997; Mulle et al., 1998; Cossart et al., 2002); (3) lesions of the mossy fibers both reduce the density of KARs (Represa et al., 1987) and suppress KAR-mediated synaptic transmission in CA3 pyramidal cells (Cossart et al., 2002); (4) the apparition of $\mathrm{EPSC}_{\mathrm{KA}}$ in CA3 pyramidal cells is correlated with the postnatal development of mossy fiber synapses (Marchal and Mulle, 2004). Furthermore, the binding profile of radioactive kainate is correlated to mossy fiber sprouting in animal models of TLE and in patients with epilepsy (Represa et al., 1987, 1989). Therefore, we asked whether the formation of aberrant mossy fiber synapses onto granule cells would trigger the expression of functional KAR-operated synapses in chronic epileptic rats.

We report that $\mathrm{EPSC}_{\mathrm{KA}} \mathrm{s}$ are involved in evoked, spontaneous, and miniature glutamatergic synaptic transmission in dentate GCs from epileptic but not control rats. $\mathrm{EPSC}_{\mathrm{KA}} \mathrm{s}$ provide a substantial component of glutamatergic transmission in GCs from 
epileptic rats, because they represent half of the glutamatergic excitatory drive. The EPSC $_{\mathrm{KA}} \mathrm{s}$ that display a slow kinetics when compared with EPSC $_{\text {AMPA }}$ are generated by recurrent mossy fiber synapses. Accordingly, blockade of KARs significantly reduces mossy fiber network-driven activities.

\section{Materials and Methods}

All experiments were approved by the Institut National de la Santé et de la Recherche Médicale Animal Care and Use Committee.

Pilocarpine treatment. Adult male Wistar rats (200-450 g; Janvier Breeding Center, Le Genest-Saint-Isle, France) were injected intraperitoneally with pilocarpine hydrochoride $(325-340 \mathrm{mg} / \mathrm{kg}) 30 \mathrm{~min}$ after a low dose of cholinergic antagonist scopolamine methyl nitrate $(1 \mathrm{mg} / \mathrm{kg}$, i.p.). Approximately $60 \%$ of the rats experienced class IV/V seizures (Racine, 1972). After $3 \mathrm{~h}$ of status epilepticus, diazepam $(8 \mathrm{mg} / \mathrm{kg})$ was injected intraperitoneally. After a seizure-free period of several weeks, the rats experienced spontaneous seizures. Only rats that experienced many spontaneous seizures, which were expected to display a high degree of mossy fiber sprouting (Tauck and Nadler, 1985), were selected for recordings (2-8 months after the pilocarpine injection; mean, $4.55 \pm 0.44$ months; chronic epileptic rats, $n=36)$. Some rats were also used $4-5 \mathrm{~d}$ after the status epilepticus (poststatus epilepticus rats, $n=2$ ). Agematched rats $(n=20)$ were used as controls.

Slice preparation. Animals were deeply anesthetized with chloral hydrate $(350 \mathrm{mg} / \mathrm{kg}$, i.p.) and decapitated. The brain was removed rapidly, the hippocampi were dissected, and transverse $400-\mu \mathrm{m}$-thick hippocampal slices were cut using a Leica VT1000S tissue slicer (Leica, Nussloch, Germany). Slices were then transferred for rest $(>1 \mathrm{~h})$ in oxygenated normal artificial CSF (ACSF) containing the following (in mM): 126 $\mathrm{NaCl}, 3.5 \mathrm{KCl}, 1.2 \mathrm{NaH}_{2} \mathrm{PO}_{4}, 26 \mathrm{NaHCO}_{3}, 1.3 \mathrm{MgCl}_{2}, 2.0 \mathrm{CaCl}_{2}$, and 10 D-glucose, $\mathrm{pH} 7.4$.

Patch-clamp recordings. Whole-cell recordings of granule cells were obtained using the "blind" patch-clamp technique in a submerged chamber (ASCF; $30-32^{\circ} \mathrm{C}$ ) in voltage-clamp mode. Tight-seal electrodes $(5-8$ $\mathrm{M} \Omega$ ) were filled with an internal solution containing the following (in mM): 135 gluconic acid, $135 \mathrm{CsOH}, 10 \mathrm{MgCl}_{2}, 0.1 \mathrm{CaCl}_{2}, 1 \mathrm{EGTA}, 10$ HEPES, 2 MgATP, $0.4 \mathrm{NaGTP}$, and $0.5 \%$ biocytin, $\mathrm{pH}$ 7.25. Whole-cell recordings were performed using an Axopatch 200A amplifier (Molecular Devices, Union City, CA). Data were filtered at $2 \mathrm{kHz}$, digitized (20 $\mathrm{kHz}$ ) with a Labmaster interface card (Molecular Devices) to a personal computer, and acquired using Axoscope 7.0 software (Molecular Devices). Signals were analyzed off-line using MiniAnalysis 6.0.1 (Synaptosoft, Decatur, GA). Access resistance ranged between 10 and $20 \mathrm{M} \Omega$, and the results were discarded if the access resistance changed by $>20 \%$. The input membrane resistance $\left(R_{\mathrm{m}}\right)$ and the membrane capacitance $\left(C_{\mathrm{m}}\right)$ were not significantly different in the dentate GCs from control $\left(C_{\mathrm{m}}=18.4 \pm 2.54 \mathrm{pF} ; R_{\mathrm{m}} 194 \pm 17.9 \mathrm{M} \Omega ; n=14\right)$ and epileptic rats $\left(C_{\mathrm{m}}=17.7 \pm 2.29 \mathrm{pF} ; R_{\mathrm{m}} 181 \pm 26.9 \mathrm{M} \Omega ; n=12\right.$; Mann-Whitney $U$ test; $p=0,777$ for $C_{\mathrm{m}}$ and $p=0,341$ for $R_{\mathrm{m}}$ ).

Electrical stimulations. Bulk and minimal stimulations were performed via a bipolar NiCh electrode or a monopolar glass electrode $(\sim 1 \mathrm{M} \Omega$; filled with ACSF), positioned in the inner one-third of the molecular layer of the dentate gyrus. For minimal stimulations, the stimulus intensity and pulse duration were progressively enhanced to the lowest values that evoked all or no EPSCs (typically between 20 and $30 \mu$ s and 30 and $50 \mathrm{~V} ; 0.2 \mathrm{~Hz}$ ). Minimal EPSCs were accepted if their amplitude exceeded twice the baseline noise and if they occurred at a constant latency $<5 \mathrm{~ms}$. The mossy fiber pathway was stimulated antidromically $(40-60 \mu \mathrm{s}$; $40-60 \mathrm{~V} ; 0.2 \mathrm{~Hz}$ ) using a bipolar NiCh electrode in the stratum lucidum CA3b as described previously (Okazaki and Nadler, 2001). Evoked responses were recorded in the granule cell layer with extracellular glass recording electrodes (2-3 M $\Omega$; filled with normal ACSF) using a DAM-80 amplifier (low filter, $1 \mathrm{~Hz}$; high filter, $3 \mathrm{KHz}$; World Precision Instruments, Sarasota, FL).

Glutamate agonist application. Focal applications of kainate (30 $\mu \mathrm{M}$ in ASCF) were performed via a glass pipette connected to a Picospritzer (General Valve, Fairfield, NJ).

Kinetic analysis. The kinetics of synaptic events was analyzed using
MiniAnalysis 6.0.1 as reported previously (Cossart et al., 2002) in a double-blind manner. To quantify the contribution of AMPARs and KARs to synaptic transmission in dentate GCs of epileptic rats, we statistically determined limits for decay times of miniature events to segregate between EPSC $_{\mathrm{AMPA}}$ and $\mathrm{EPSC}_{\mathrm{KA}}$ with a 95\% confidence interval. For this purpose, we used the Gaussian curve fitting of the histogram plots of decay times of all mEPSCs. The experiments performed in the presence of AMPAR antagonists [100 $\mu \mathrm{M}$ 1-(4-aminophenyl)-4-methyl-7,8methylenedioxy-5H-2,3-benzodiazepine (GYKI 52466) or $1 \mu \mathrm{M} \mathrm{2,3-}$ dihydroxy-6-nitro-7-sulfonyl-benzo[f $f$ quinoxaline-7-sulfonamide (NBQX)] or a KAR blocker [10 $\mu \mathrm{M}(2 S, 4 R)$-4-methylglutamic acid (SYM 2081)] enabled us to determine the statistical limit to classify miniature events as EPSC $_{\mathrm{KA}}$ (see Fig. $3 C$, right) (decay time, $>5.9 \mathrm{~ms} ; p<0.05$ ) or EPSC $_{\text {AMPA }}$ (see Fig. $4 C$, right) (decay time, $<5.5 \mathrm{~ms} ; p<0.05$ ), respectively. Using these kinetic limits, selected $\mathrm{EPSC}_{\mathrm{KA}} \mathrm{s}$ and $\mathrm{EPSC}_{\mathrm{AMPA}} \mathrm{s}$ fall beyond a $5 \%$ confidence interval for pharmacologically isolated $\mathrm{EPSC}_{\mathrm{AMPA}}$ and $\mathrm{EPSC}_{\mathrm{KA}}$, respectively. Furthermore, $<5 \%$ of the total non-NMDAR-mediated miniature events could not be classified as EPSC $_{\mathrm{AMPA}}$ or EPSC $_{\mathrm{KA}}$ in our experimental conditions. The charge transfer through the AMPAR- and KAR-mediated EPSC was calculated as described previously (Cossart et al., 2002).

Statistical analysis. All values are given as means \pm SEM. Statistical analyses were performed using SigmaStat 3.1 (Systat Software, Richmond, CA). For comparison between two groups, the unpaired Student's $t$ test was used if the data passed the normality test and the equal variance test; otherwise, the Mann-Whitney rank-sum test was used. For comparison of one group before and after a pharmacological or physiological treatment, the paired Student's $t$ test was used if the data passed the normality test; otherwise, the Wilcoxon signed rank test was used. To compare two Gaussian distributions, the Kolmogorov-Smirnov test was performed. To compare two cumulative probability plots, the $\chi^{2}$ test was performed. The level of significance was set at $p<0.05 . n$ refers to the number of cells except when indicated otherwise.

Morphological analysis. Timm staining was performed routinely on sections used for electrophysiological recordings (Tauck and Nadler, 1985; Wuarin and Dudek, 2001). In brief, sections were incubated for 15 min in an $\mathrm{Na}_{2} \mathrm{~S}$ solution and fixed with $4 \%$ paraformaldehyde. Slices were resectioned in a cryostat ( $40 \mu \mathrm{m}$ thick) and processed with the Timm solution (Represa et al., 1987). For immunofluorescence analysis, rats were deeply anesthetized and perfused with $4 \%$ paraformaldehyde in PBS. Hippocampal sections ( $40 \mu \mathrm{m}$ thick) were obtained with a vibratome and incubated with either rabbit anti-glutamate receptor $2 / 3$ (GluR2/3; 1:100; Chemicon, Temecula, CA) or vesicular glutamate transporter 1 (VGLUT1; 1:1000; Synaptic Systems, Goettingen, Germany) followed by goat anti-rabbit cyanine 3-conjugated (1:200; The Jackson Laboratory, Bar Harbor, ME). In all cases, no labeling was detected when specific antibodies were replaced with normal rabbit or mouse serum. Semiquantitative analyses of the intensity of immunolabeling were performed on optical sections obtained with an Olympus fluoview-500 laser-scanning microscope (Olympus Optical, Tokyo, Japan) using a $20 \times$ lens. For each control and pilocarpine animal, fluorescence intensity was measured in the granule cell layer and molecular layer of the dentate gyrus (eight different hippocampal sections from five different animals). The corpus callosum was used as a reference value for background. All images were acquired with the same scanning conditions. Statistical analyses were performed using ANOVA and Student's $t$ tests. The identity of recorded cells was assured by the revelation of the biocytin injected through the patch pipette accordingly to the protocol used previously (Cossart et al., 2002). Only well defined granule cells were considered in the present study.

Chemicals. Drugs were purchased from Sigma (St. Louis, MO) (TTX, 4-AP, biocytin, pilocarpine hydrochloride, and scopolamine methyl nitrate), Tocris Neuramin (Bristol, UK) [GYKI 52466, SYM 2081, bicuculline, NBQX, CNQX, D-APV, 2-(2,3-dicarboxycyclopropyl)-glycine (DCGIV), forskolin (FSK), and kainate], and Roche (Basel, Switzerland) (diazepam). 


\section{Results}

Sprouting of mossy fibers in chronic epileptic rats

As in previous studies (Sutula et al., 1988; Mello et al., 1993; Represa et al., 1993; Okazaki et al., 1995; Buckmaster et al., 2002), an extensive sprouting of mossy fibers was observed in the dentate gyrus of chronic epileptic rats months after the pilocarpine injection and the inaugurating status epilepticus. Using Timm staining to reveal mossy fiber boutons, both the granule cell layer and the inner one-third of the molecular layer of the dentate gyrus were labeled in chronic epileptic rats (Fig. $1 E$ ), whereas only the hilar polymorph layer was labeled in controls (Fig. 1A). Because mossy fibers are glutamatergic (Henze et al., 2000), antibodies to VGLUT1, which specifically stain glutamatergic terminals (Fremeau et al., 2004), were also used to assess mossy fiber sprouting (Fig. $1 B, F$ ). Instead of the uniform staining with fine spots observed in control slices (Fig. $1 B$, inset), larger and brighter spots (Fig. $1 F$, inset) were observed in regions corresponding to recurrent mossy fiber terminal zones (i.e., the dentate granular and inner molecular layers) but not in other regions in which sprouting did not take place. According to this, we found a significant increase in VGLUT1 immunoreactivity in the inner molecular layer and the granular layer (by $152.4 \pm 15.4 \%$; unpaired $t$ test; $p=0.001$ ) but not in other regions (i.e., the outer molecular layer $p=0.76$ ). The bigger spots displayed similar features than those observed in the CA3 stratum lucidum (data not shown) and may correspond to the newly formed mossy fiber synapses that are of larger size than other glutamatergic synapses and are highly enriched in clear, round synaptic vesicles (Represa et al., 1993). Therefore, the dentate gyrus from chronic epileptic rats displays sprouting of glutamatergic mossy fibers in our experimental conditions.

\section{Kainate receptor-mediated synaptic events in granule cells from chronic epileptic but not control rats}

In control GCs, low-frequency stimulations $(0.033 \mathrm{~Hz})$ in the inner one-third of the molecular layer evoked a synaptic current with a rapid decay in the continuous presence of antagonists of $\mathrm{GABA}_{\mathrm{A}}(10 \mu \mathrm{M}$ bicuculline $)$ and NMDA (40 $\left.\mu \mathrm{M} \mathrm{D}-\mathrm{APV}\right)$ receptors (Fig. $1 C$, left). This current was mediated by AMPA receptors, because it was completely blocked by the AMPAR antagonist GYKI 52466 (Fig. 1C, middle) $(100 \mu \mathrm{M} ; n=5)$, even when repetitive stimulations were applied (Fig. $1 C$, right) (10 stimuli at $30 \mathrm{~Hz})$. In dentate GCs from chronic epileptic rats $(n=5)$, lowfrequency stimulations $(0.033 \mathrm{~Hz})$ of recurrent mossy fibers in the inner one-third of the molecular layer evoked a synaptic current with a fall composed of both a rapid and a slow component (Fig. $1 G$, left) $(n=5)$. Application of GYKI $52466(100 \mu \mathrm{M})$ blocked the rapid component but not the slow component (Fig. $1 G$, middle). The slow component was mediated by KARs, because it was subsequently blocked by the mixed AMPAR/KAR antagonist CNQX (Fig. 1G, right) $(50 \mu \mathrm{M})$. Therefore, stimulation in the inner one-third of the dentate molecular layer evoked KAR-mediated synaptic responses in dentate granule cells from epileptic rats but not control rats.

We next tested whether KARs can be activated by the spontaneous release of glutamate (Cossart et al., 2002) in dentate GCs from epileptic rats. Dentate GCs were recorded at the reversal potential for GABAergic currents $\left(V_{\mathrm{h}}=-70 \mathrm{mV}\right)$, a potential at which NMDAR-mediated currents are also abolished by $\mathrm{Mg}^{2+}$ block (Ascher and Nowak, 1988). In dentate GCs from epileptic rats, the frequency of spontaneous EPSCs was significantly higher than that in control rats (compare Fig. $1 D, H)(1.65 \pm 0.54 \mathrm{~Hz}$, $n=18$ and $0.41 \pm 0.06 \mathrm{~Hz}, n=17$, respectively; Mann-Whitney;
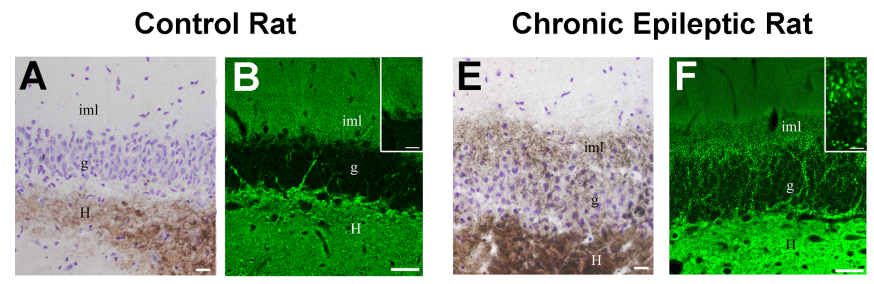

C

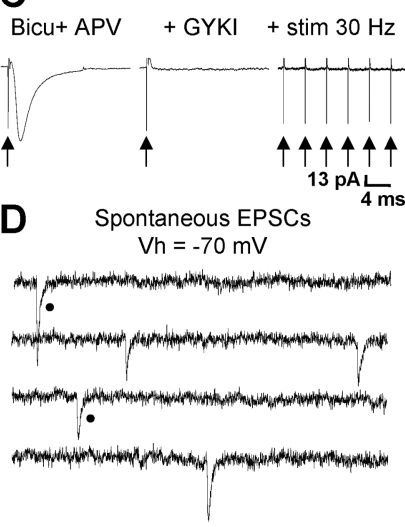

G

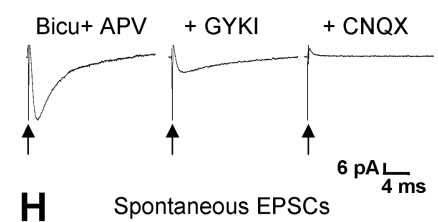

$4 \mathrm{~ms}$ $\mathrm{Vh}=-70 \mathrm{mV}$

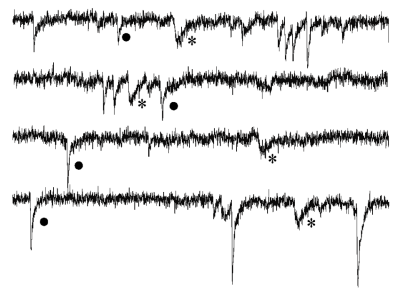

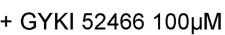
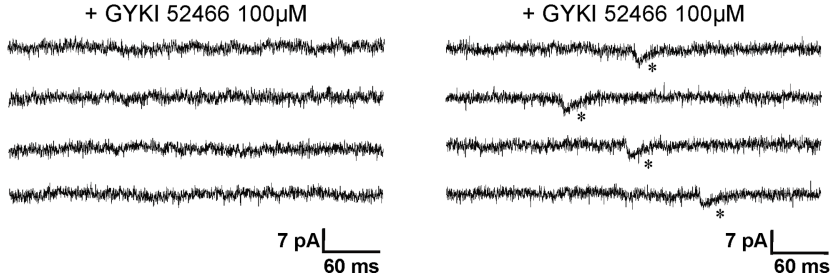

Figure 1. Mossy fiber sprouting and EPSC $C_{K A}$ in granule cells from epileptic rats. $A, E$, Timm staining (dark brown; counterstained with cresyl violet) of mossy fibers of control $(\boldsymbol{A})$ and epileptic $(\boldsymbol{E})$ rat sections after electrophysiological recordings. In chronic epileptic rats, mossy fiber collaterals invade the granule cell layer $(\mathrm{g})$ and the inner third of the molecular layer (iml). Scale bars, $20 \mu \mathrm{m} . \boldsymbol{B}, \boldsymbol{F}$, VGLUT1 immunostaining of sections from control $(\boldsymbol{B})$ and epileptic $(\boldsymbol{F})$ rats. In epileptic rats, the staining dramatically increases in the inner molecular layer (iml) and granule cell layer, in good correlation with the sprouting of mossy fibers. In the inner molecular layer, the type of staining is modified, as large spots (characteristic of the staining of large mossy fiber synaptic boutons) have replaced the fine speckled staining observed in the control (enlarged in the insets). Scale bars, $50 \mu \mathrm{m}$; insets, $10 \mu \mathrm{m}$. C, G, Averages of 30 individual EPSCs to stimulations $(0.033 \mathrm{~Hz})$ in the inner one-third of the molecular layer of the dentate gyrus recorded in the presence of $10 \mu \mathrm{m}$ bicuculline (Bicu) and $40 \mu \mathrm{m}$ D-APV (APV). In control granule cells ( $\boldsymbol{C}$, the EPSC evoked in control conditions (left) was completely blocked by AMPA receptor antagonist GYKI 52466 (GYKI; $100 \mu \mathrm{m}$; middle), even when repetitive stimulations were applied (10 stimuli at $30 \mathrm{~Hz}$; stim $30 \mathrm{~Hz}$; right). In dentate $\mathrm{GCs}$ from epileptic rats $(\boldsymbol{G})$, the EPSC evoked in control conditions displayed a rapid and a slow decay (left). Application of GYKI 52466 (GYKl; $100 \mu \mathrm{m}$ ) blocked the rapid but not the slow component (middle); the slow component was subsequently abolished by the mixed AMPAR/KAR antagonist CNQX (50 $\mu \mathrm{m}$; right). $\boldsymbol{D}, \boldsymbol{H}$, Representative $s E P S C$ recordings ( $V_{\mathrm{h}}=-70 \mathrm{mV}$ in this and subsequent figures) from a control granule cell $(\boldsymbol{D})$ and a granule cell from pilocarpine-treated rat $(\boldsymbol{H})$, showing that the nonNMDAR-mediated synaptic transmission is enhanced in epileptic tissue. Note that in control tissue, all of the synaptic events are fast (filled circle; $\boldsymbol{D}$ ) and mediated by AMPARs, because they are fully abolished by $100 \mu \mathrm{m}$ GYKI 52466 (D). In contrast, in the epileptic tissue, the nonNMDAR-mediated synaptic transmission additionally includes slow events (asterisk; $\boldsymbol{H}$ ) that are resistant to $100 \mu \mathrm{M}$ GYKI $52466(\boldsymbol{H})$.

$p=0.021$ ) as reported previously (Wuarin and Dudek, 2001). Visual inspection of EPSCs revealed the presence of events with fast and slow kinetics in GCs from epileptic rats, whereas only fast events were observed in control cells (compare Fig. $1 D, H$ ). The fast events recorded in control GCs were mediated by AMPARs, because they were all blocked by GYKI 52466 (Fig. 1D) (100 $\mu \mathrm{M}$; $n=5)$. The slow EPSCs recorded in GCs from epileptic rats were mediated by KARs, because they were resistant to GYKI 52466 
(Fig. $1 H)(100 \mu \mathrm{M} ; n=5)$ and fully abolished by the mixed AMPAR/KAR antagonist CNQX (50 $\mu \mathrm{M} ; n=5$; data not shown). In control GCs, the nonobservation of slow EPSC $_{\mathrm{KA}}$ could result from the low frequency of spontaneous synaptic activity in these cells. To address this, we artificially increased the spontaneous synaptic activity in control cells using 4-AP (50-100 $\mu \mathrm{M})$, a potassium channel antagonist, in the continuous presence of bicuculline $(10 \mu \mathrm{M})$ and D-APV $(40 \mu \mathrm{M})$. In the presence of 4-AP, the frequency of spontaneous EPSCs recorded in control GCs was drastically increased (Fig. 2A-C) (from $0.41 \pm 0.08$ to $1.61 \pm 0.32 \mathrm{~Hz} ; n=5$; Mann-Whitney; $p=0.008$ ) and was not significantly different from that observed in GCs from epileptic rats (Fig. $2 C)(n=$ 18; Mann-Whitney; $p=0.146$ ). In these conditions, all non-NMDAR-mediated EPSCs were fully abolished by AMPAR antagonists NBQX (Fig. 2A,B) $(1 \mu \mathrm{M} ; n=3)$ (Bureau et al., 1999; Cossart et al., 2002) or GYKI 52466 (100 $\mu \mathrm{M} ; n=2)$. Thus, KARs contribute to the spontaneous and evoked synaptic transmission in granule cells from chronic epileptic rats but not control rats.

To determine whether the contribution of KARs to spontaneous synaptic transmission in GCs occurred before or after the onset of chronic epilepsy, we recorded spontaneous non-NMDAR-mediated EPSCs in 4- to 5-d-poststatus epilepticus rats that did not express behavioral seizures and showed no evidence of mossy fiber sprouting using Timm staining (data not shown). The frequency of spontaneous EPSCs recorded in GCs from 4 - to 5-d-poststatus epilepticus rats was not significantly different from that recorded in control GCs $(0.45 \pm 0.17 \mathrm{~Hz}, n=$ 5 and $0.41 \pm 0.06 \mathrm{~Hz}, n=17$, respectively; Mann-Whitney; $p=$ 1.00) (supplemental Fig. $S 1 A, C$, available at www.jneurosci.org as supplemental material), as reported previously (Wuarin and Dudek, 2001). Visual inspection of EPSCs revealed the presence of events with fast kinetics only that were all blocked by the AMPAR antagonist GYKI 52466 (100 $\mu \mathrm{M} ; n=5$; data not shown). As in control GCs, the nonobservation of slow EPSC KA $_{\text {in }}$ GCs from 4- to 5-d-poststatus epilepticus rats could result from the low frequency of spontaneous synaptic activity in these cells. Therefore, we increased the spontaneous synaptic activity in GCs from 4 - to 5-d-poststatus epilepticus rats using 4-AP (100 $\mu \mathrm{M})$ in the continuous presence of bicuculline $(10 \mu \mathrm{M})$ and D-APV $(40 \mu \mathrm{M})$. In the presence of $4-\mathrm{AP}$, the frequency of spontaneous EPSCs was drastically increased (from $0.45 \pm 0.17$ to $4.57 \pm 1.22 \mathrm{~Hz} ; n=5$; paired $t$ test; $p=0.028$ ) (supplemental Fig. S1 $A, C$, available at www.jneurosci.org as supplemental material). In these conditions, all non-NMDAR-mediated EPSCs were fully abolished by AMPAR antagonists NBQX ( $1 \mu \mathrm{M}$; $n=3$ ) (supplemental Fig. S1 A, B, available at www.jneurosci.org as supplemental material) or GYKI 52466 (100 $\mu \mathrm{M} ; n=$ 2 ). In conclusion, KARs contribute to synaptic transmission in granule cells from chronic epileptic rats but not control rats or 4- to 5-d-poststatus epilepticus rats.

\section{Kinetics of $\mathrm{mEPSC}_{\mathrm{AMPA}}$ and $\mathrm{mEPSC}_{\mathrm{KA}}$ in granule cells from epileptic rats}

We next characterized the kinetics of pharmacologically isolated $\mathrm{mEPSC}_{\mathrm{AMPA}}$ and $\mathrm{mEPSC}_{\mathrm{KA}}$ to subsequently determine their contribution to synaptic activity in the absence of any antagonist (Cossart et al., 2002). Miniature EPSCs (mEPSCs) were recorded in the presence of TTX $(1 \mu \mathrm{M})$, bicuculline $(10 \mu \mathrm{M})$, and D-APV $(40 \mu \mathrm{M})$ to isolate non-NMDAR-mediated glutamatergic events. There was no significant difference between the frequencies of miniature glutamatergic events recorded in dentate GCs from control rats and those from chronic epileptic rats $(0.25 \pm 0.09 \mathrm{~Hz}$ for controls, $n=14$ and $0.27 \pm 0.06 \mathrm{~Hz}$ for epileptic rats, $n=12$; Mann-Whitney; $p=0.487)$. However, we observed a significant shift toward slower values when comparing the cumulative probability plots of decay times of all mEPSCs recorded in GCs from epileptic and control rats (Fig. 3D) ( $\chi^{2}$ test; $\left.p<0.001\right)$. In GCs from control rats $(n=14)$, all miniature events displayed a fast kinetics (Fig. 3A) and clustered in one area of the graph in scatter plots of $10-90 \%$ rise times versus decay times (Fig. $3 B$ ). The histogram of the decay times of miniature events revealed that fast events belonged to one population, because their distribution was best fitted by one Gaussian curve (Fig. 3C, left). All of these events were mediated by AMPARs, because they were fully blocked by NBQX (Fig. 3A) $(1 \mu \mathrm{M} ; n=9)$ or GYKI 52466 (100 $\mu \mathrm{M} ; n=5 ; \mathrm{mEPSC}_{\mathrm{AMPA}} ; r=1.29 \pm 0.07 \mathrm{~ms} ; \tau=3.26 \pm 0.18 \mathrm{~ms}$; $n=14)$.

In GCs from epileptic rats $(n=12)$, we observed slow, miniature events $\left(\mathrm{mEPSC}_{\text {slow }}\right.$ ) in addition to the fast events $\left(\right.$ mEPSC $_{\text {fast }}$ ) (Fig. $3 A$ ). mEPSCs clustered within two separated 
A

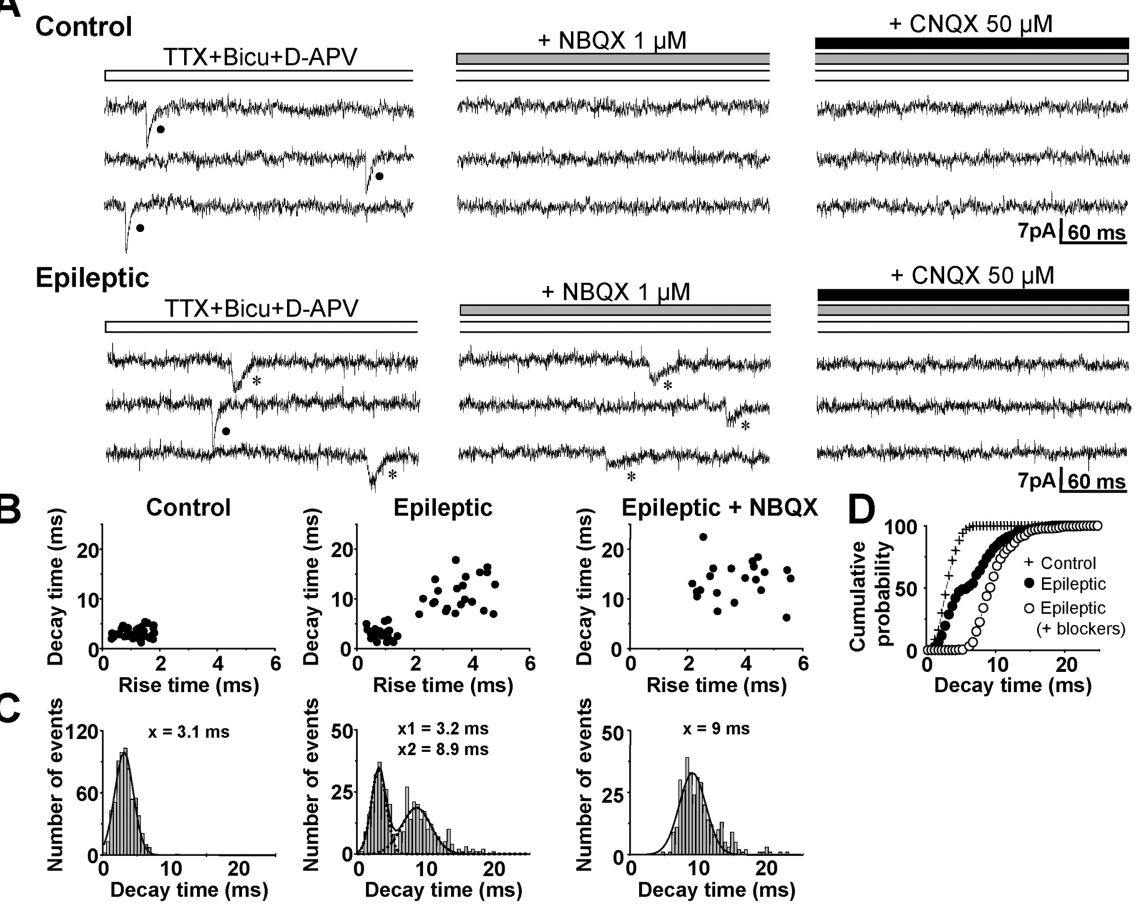

Figure 3. $\mathrm{mEPSC}_{\mathrm{KA}}$ can be pharmacologically isolated in the presence of AMPA receptor antagonists in granule cells from epileptic rats. $A, \mathrm{mEPSC}$ recordings in the presence of $1 \mu \mathrm{m} \mathrm{TTX}, 10 \mu \mathrm{m}$ bicuculline (Bicu), and $40 \mu \mathrm{m} \mathrm{D}$-APV in a granule cell from control and epileptic rats. In the control cell, $m$ EPSCs have only fast kinetics. In the cell from an epileptic rat, fast (filled circles) and slow (asterisk) events can be recorded. Fast events are mediated by AMPARs, because they are blocked by $1 \mu \mathrm{m} \mathrm{NBQX}$. Slow mEPSCs are mediated by KARs, because they are NBQX resistant and abolished by $50 \mu \mathrm{m}$ CNQX. B, Scatter plots of mEPSC $10-90 \%$ rise times versus decay times in a granule cell from a control and epileptic rat. Note that in the granule cell from an epileptic rat, events cluster in two separate areas of the graph, in contrast to the control cell. In the presence of $1 \mu \mathrm{MNBQX}$, only events with a slow time course are present in the granule cell from an epileptic rat. C, Distribution of decay times of all mEPSCs in granule cells from control (left) and epileptic (middle) rats. In granule cells from epileptic rats, the distribution is fitted with two Gaussian curves (dotted lines; mean, 3.2 and $8.9 \mathrm{~ms}$, respectively) in contrast to control neurons (mean, $3.1 \mathrm{~ms}$ ). In granule cells from epileptic rats, only mEPSCs with a slow decay time (346 events recorded in 11 cells; right) are resistant to AMPAR antagonists ( $1 \mu \mathrm{m} \mathrm{NBQX} \mathrm{or} 100$ $\mu \mathrm{M}$ GYKI 52466); the distribution is now fitted by one Gaussian curve (mean, $9 \mathrm{~ms}$ ). $\boldsymbol{D}$, Cumulative probability plot of the decay time constant of all mEPSCs in granule cells from control (cross) and epileptic (filled circle) rats. In granule cells from epileptic rats, the decay time distribution is significantly shifted toward slower values $\left(\chi^{2}\right.$ test; $\left.p<0.001\right)$. The addition of AMPAR antagonists (1 $\mu \mathrm{m} \mathrm{NBQX}$ or $100 \mu \mathrm{m}$ GYKI 52466) further shifted the curve toward slower values (open circle; $\chi^{2}$ test; $p<0.01$ ) in accordance with the blockade of fast EPSC $_{\text {AMPA. }}$.

areas of the graph in scatter plots of $10-90 \%$ rise times versus decay times (Fig. 3B). The histogram of the decays of miniature events revealed that $\mathrm{mEPSC}_{\text {fast }}$ and $\mathrm{mEPSC}_{\text {slow }}$ belonged to two distinct populations, because it was best fitted by two statistically different Gaussian curves (Fig. 3C, middle) (Kolmogorov-Smirnov; $p<0.005)$. Bath applications of AMPAR antagonists $(1 \mu \mathrm{M}$ NBQX, $n=6$; or $100 \mu \mathrm{M}$ GYKI 52466, $n=5$ ) selectively suppressed the fast events (Fig. 3A) as shown by the histogram of the decay times (compare Fig. $3 C$, middle and right) and the cumulative probability plot of the decay times (Fig. $3 D$ ) as well as the plot of $10-90 \%$ rise times versus decay times (Fig. 3B). The miniature events that remained in the presence of AMPAR antagonists were mediated by KARs, because they were fully abolished by the mixed AMPAR/KAR antagonist CNQX (Fig. $3 A)(50 \mu \mathrm{M}$; $\left.\mathrm{mEPSC}_{\mathrm{KA}}, r=2.53 \pm 0.28 ; \tau=9.83 \pm 0.82 ; n=11\right) . \mathrm{mEPSC}_{\mathrm{KA}}$ and mEPSC $_{\text {slow }}$ (recorded in the absence of the AMPAR antagonist) represented the same population of events, because the Gaussian curve fitting the mEPSC $_{\mathrm{KA}}$ distribution and the one fitting $\mathrm{mEPSC}_{\text {slow }}$ were not significantly different (compare Fig. $3 C$, right and middle) (Kolmogorov-Smirnov; $p>0.1$ ). In keeping with this, the group of events obtained when plotting 10-90\% rise times versus decay times of $\mathrm{mEPSC}_{\mathrm{KA}}$ overlapped that of
mEPSC $_{\text {slow }}$ but not that of mEPSC $_{\text {fast }}$ (Fig. $3 B)$. To pharmacologically isolate mEPSC $_{\text {AMPA }}$ in GCs from epileptic rats, we used bath application of SYM 2081 $(n=5)$, a compound that selectively desensitizes KARs (DeVries and Schwartz, 1999; Li et al., 1999). SYM $2081(10 \mu \mathrm{M})$ blocked the slow events (Fig. 4A) as shown by the histogram (Fig. 4C) and the cumulative probability plot of the decay times of miniature events (Fig. 4D) as well as the plot of $10-90 \%$ rise times versus decay times (Fig. 4B). In the presence of SYM 2081, the remaining fast miniature events were mediated by AMPARs, because they were fully abolished by GYKI 52466 (Fig. $4 A)\left(100 \mu \mathrm{M} ; \operatorname{mEPSC}_{\mathrm{AMPA}} ; r=1.20 \pm\right.$ $0.28 ; \tau=3.15 \pm 0.31 ; n=5)$. mEPSC $_{\text {AMPA }}$ and $\mathrm{mEPSC}_{\text {fast }}$ (recorded in the absence of the KAR antagonist) represented the same population of events, because the Gaussian curve fitting the $\mathrm{MEPSC}_{\mathrm{AMPA}}$ distribution and the one fitting $\mathrm{mEPSC}_{\text {fast }}$ were not significantly different (compare Fig. $4 C$, left and right) (Kolmogorov-Smirnov; $p>0.1$ ). In keeping with this, the group of events obtained when plotting $10-90 \%$ rise times versus decay times of mEPSC $_{\text {AMPA }}$ overlapped that of mEPSC $_{\text {fast }}$ but not that of mEPSC $_{\text {slow }}$ (Fig. $4 B$ ). Furthermore, the kinetics of $\mathrm{mEPSC}_{\mathrm{AMPA}}$ recorded in control GCs and those pharmacologically isolated in GCs from epileptic rats were not significantly different because of the following: (1) the Gaussian curve fitting the distribution of mEPSC $_{\mathrm{AMPA}}$ in the presence of SYM 2081 in GCs of epileptic rats and the one fitting mEPSC $_{\mathrm{AMPA}}$ in control GCs were not significantly different (compare Figs. 3C, left, $4 C$, right) (Kolmogorov-Smirnov; $p>$ 0.1 ; (2) in cumulative probability plots, the distribution of mEPSCs recorded in GCs from epileptic rats in the presence of SYM 2081 was not significantly different from that recorded in control GCs (Fig. $4 D$ ) ( $\chi^{2}$ test; $p>0.1$ ); and (3) they had similar rise and decay time mean values (unpaired $t$ test; $p=0.776$ for $10-90 \%$ rise time and $p=0.667$ for decay time) (supplemental table, available at www.jneurosci.org as supplemental material).

We conclude that in GCs from epileptic rats but not control rats, the quantal release of glutamate generates slow EEPSC $_{\mathrm{KA}}$ in addition to fast $\mathrm{mEPSC}_{\mathrm{AMPA}}$.

Kainate receptors provide half of the spontaneous and miniature glutamatergic currents in granule cells from epileptic rats

To quantify the contribution of AMPARs and KARs to synaptic transmission in dentate GCs from epileptic rats, we statistically determined limits for decay times to segregate $\mathrm{EPSC}_{\mathrm{AMPA}}$ and EPSC $_{\mathrm{KA}}$ in the absence of AMPAR or KAR antagonists (see Materials and Methods). The mean rise and decay time values of $\mathrm{EPSC}_{\mathrm{AMPA}}$ and $\mathrm{EPSC}_{\mathrm{KA}}$ selected using these decay time limits were not significantly different from those of pharmacologically isolated events $\left(n=12\right.$; paired $t$ test; $\mathrm{mEPSC}_{\mathrm{AMPA}}, p=0.150$ for 
$10-90 \%$ rise time and $p=0.646$ for decay time; $\mathrm{mEPSC}_{\mathrm{KA}}, p=0.428$ for $10-90 \%$ rise time and $p=0.610$ for decay time) (supplemental table, available at www. jneurosci.org as supplemental material).

Using the kinetic limits, we found that the frequencies were $0.15 \pm 0.05$ and $0.12 \pm 0.02 \mathrm{~Hz}$ for mEPSC $_{\mathrm{KA}}$ and $\mathrm{mEPSC}_{\mathrm{AMPA}}$, respectively $(n=12)$. Thus, $\mathrm{mEPSC}_{\mathrm{KA}}$ represented half of the miniature non-NMDA glutamatergic synaptic events $(50.8 \pm 6.63 \%$; $n=12)$. We extended this analysis by calculating the mean charge carried by KARs and AMPARs in digitally averaged $\mathrm{mEPSC}_{\mathrm{KA}}$ and $\mathrm{mEPSC}_{\mathrm{AMPA}}$. We observed that, as reported previously in other cell types (Frerking and Nicoll, 2000; Cossart et al., 2002), the mean charge transferred during EPSC $_{\mathrm{KA}}$ was significantly higher than that during $\operatorname{EPSC}_{\mathrm{AMPA}}(n=12$; MannWhitney; $p=0.014)$. Considering the frequency of synaptic events and the charge transferred, we estimated that KARs provided as much as half of the total current mediated by non-NMDARs in dentate GCs from pilocarpine-treated rats (56.2 \pm $5.98 \%$; $n=12$ ). We next determined the contribution of KARs to the spontaneous activity. The same limits for decay times were used to segregate between spontaneous EPSC $_{\mathrm{KA}}$ and $\mathrm{EPSC}_{\mathrm{AMPA}}$. We found that a significant part of non-NMDARmediated spontaneous events recorded in GCs from pilocarpine-treated rats was mediated by KARs $(45.48 \pm 6.81 \%$; $n=$ 18). Considering the frequency and the charge transferred, we estimated that half $(52.0 \pm 6.73 \% ; n=18)$ of the non-NMDAR-mediated spontaneous glutamatergic drive on dentate GCs was mediated by KARs in pilocarpine-treated rats.

Therefore, KARs are major contributors to miniature and spontaneous synaptic transmission in granule cells from chronic epileptic rats. We then determined whether EPSC $_{\mathrm{KA}}$ s were generated by recurrent mossy fibers in these cells.

Single EPSC $_{\mathrm{KA}}$ evoked by minimal stimulation shows pharmacological and physiological features of recurrent mossy fiber synapses in granule cells from epileptic rats Minimal stimulations were performed in the inner one-third of the molecular layer to stimulate single recurrent mossy fibers in the presence of a high-divalent cation concentration $(8 \mathrm{mM}$ $\mathrm{Ca}^{2+}$ ), $10 \mu \mathrm{M}$ bicuculline, and $40 \mu \mathrm{M} \mathrm{D}-\mathrm{APV}$. All-or-none EPSCs (Fig. 5A) with slow kinetics similar to mEPSC $_{\mathrm{KA}}$ could be evoked in GCs from epileptic rats (supplemental table, available at www. jneurosci.org as supplemental material). These EPSCs were mediated by KARs, because they were resistant to applications of NBQX (1 $\mu \mathrm{M})$ but fully blocked by CNQX (Fig. $5 A, B)(50 \mu \mathrm{M}$;

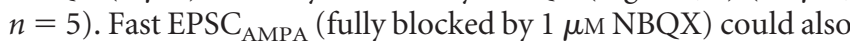
be evoked ( $n=2$; data not shown).

To ensure that minimally evoked EPSC $_{\mathrm{KA}}$ s were specifically generated by mossy fibers, we relied on the well established sensitivity of mossy fiber EPSCs to the metabotropic GluR2/3
(mGluR2/3) agonist DCGIV (Kamiya et al., 1996). In pilocarpine-treated animals, this agent also reduced synaptic transmission at recurrent mossy fiber synapses (Feng et al., 2003). Applications of DCGIV $(1 \mu \mathrm{M})$ enhanced significantly the failure

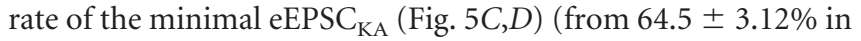
control to $92.6 \pm 1.39 \%$ in the presence of DCGIV; washout, $69.7 \pm 3.89 \% ; n=6$; paired $t$ test; $p<0.001$ ). In contrast, the amplitude of the eEPSC $\mathrm{KA}_{\mathrm{A}}$ was not changed (Fig. 5C) (control, $4.04 \pm 0.54 \mathrm{pA}$; DCGIV, $3.71 \pm 0.19 \mathrm{pA} ; n=6$; paired $t$ test; $p=$ 0.549 ). We also relied on the selective form of frequency facilitation expressed both by control and recurrent mossy fiber EPSCs (Salin et al., 1996; Feng et al., 2003). We found that increasing the frequency of stimulation from 0.2 to $1 \mathrm{~Hz}$ reduced the failure rate of the minimal eEPSC ${ }_{\mathrm{KA}}$ from $78.8 \pm 7.96 \%$ at $0.2 \mathrm{~Hz}$ to $51.2 \pm$ $7.68 \%$ at $1 \mathrm{~Hz}$ (Fig. $5 E, F)(n=5$; paired $t$ test; $p=0.037)$. Enhancing further the frequency of stimulation from 1 to $10 \mathrm{~Hz}$ did not decrease further the failure rate (Fig. $5 E, F$ ) (failure rate at $10 \mathrm{~Hz}, 51.9 \pm 11.2 \%$; paired $t$ test; $p=0.928)$. Therefore, $\mathrm{EPSC}_{\mathrm{KA}}$ evoked in the granule cells from epileptic rats displayed specific pharmacological and physiological features of mossy fiber synapses.

Recurrent mossy fibers generate both $\mathrm{EPSC}_{\mathrm{KA}}$ and EPSC $_{\mathrm{AMPA}}$ in granule cells from epileptic rats

To further identify mEPSCs generated by recurrent mossy fibers in GCs from epileptic rats, we tested the effect of FSK, an adenylyl cyclase activator, which has been shown to selectively enhance 


\section{Epileptic Rat}

A

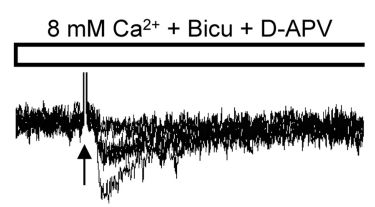

B
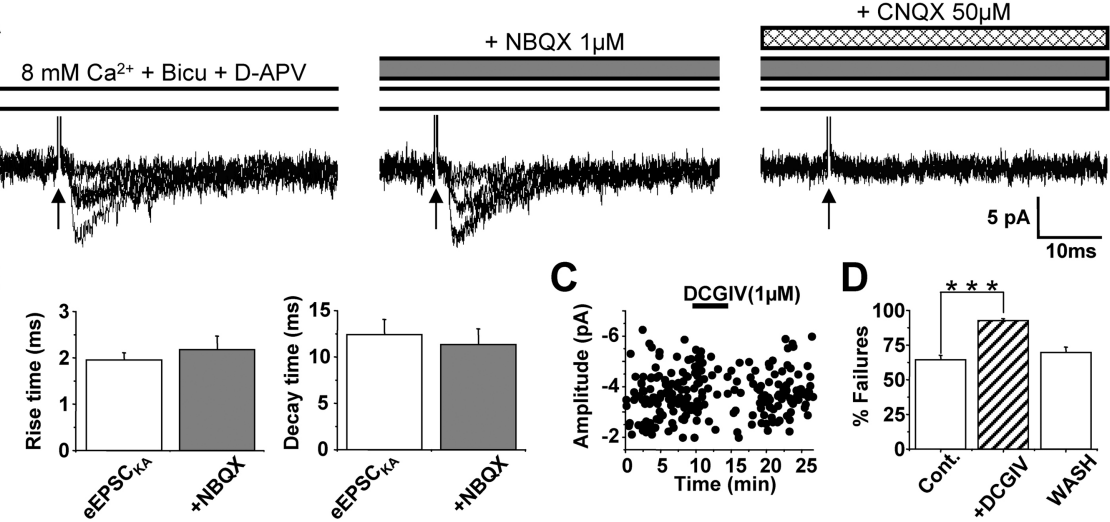

E
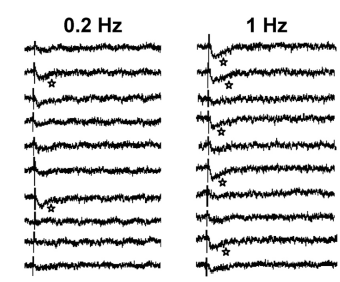

F

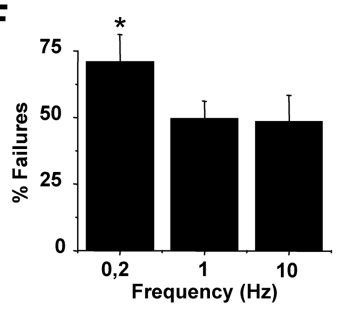

Figure 5. Single EPSC $\mathrm{KA}_{\mathrm{A}}$ are evoked by minimal stimulation of mossy fibers in granule cells from epileptic rats. $\boldsymbol{A}$, Left, Representative superimposed recordings of minimally evoked unitary EPSCs (eEPSC $; n=6)$ in granule cells from epileptic rats. Minimal stimulations (arrow) were performed in $8 \mathrm{~mm} \mathrm{Ca}{ }^{2+}, 10 \mu \mathrm{m}$ bicuculline (Bicu), and $40 \mu \mathrm{m}$ D-APV. Unitary events evoked in these conditions are mediated by KARs (eEPSC ${ }_{K A}$ ), because they are resistant to $1 \mu \mathrm{M} \mathrm{NBQX} \mathrm{(middle)} \mathrm{and} \mathrm{are} \mathrm{fully} \mathrm{abolished} \mathrm{by} 50 \mu \mathrm{M}$ CNQX (right). $\boldsymbol{B}$, Bar graphs of averaged values of rise times (left) and decay times (right) show that the time course of unitary slow events and NBQX $(1 \mu \mathrm{m})$-resistant events recorded in dentate granule cells of epileptic rats $(n=5)$ are not significantly different (paired $t$ test; $p=0.480$ for $10-90 \%$ rise times and $p=0.180$ for decay times). $C$, The plot of amplitude of unitary eEPSC $C_{\mathrm{KA}}$ versus time shows that $1 \mu \mathrm{M}$ DCGIV (mGluR2/3 agonist) does not change their amplitude but increases their failure rate (see also D). D, Bar graphs of the mean failure rate of unitary eEPSC $\mathrm{KA}_{\mathrm{KA}}$ calculated before (Cont.), during, and after (wash) application of $1 \mu \mathrm{M}$ DCGIV. Note that the mGluR2/3 agonist significantly increases the failure rate of eEPSC $\left.\mathrm{KA}{ }^{* * *} p<0.001 ; n=6\right) . E, F$, Consecutive traces of unitary eEPSC $\mathrm{KA}_{\mathrm{KA}}(n=10)$ minimally stimulated at $0.2,1$, and $10 \mathrm{~Hz}(\boldsymbol{E})$ and bar graphs of the mean failure rate of these events calculated for each frequency $(\boldsymbol{F} ; 50$ stimulations for each frequency in 6 cells) show that increasing the stimulation rate from 0.2 to $1 \mathrm{~Hz}$ resulted in a significant reduction of failures $\left({ }^{*} p<0.05\right)$; increasing the frequency of stimulation from 1 to $10 \mathrm{~Hz}$ does not further decrease the failure rate $(p>0.05)$.

synaptic transmission at mossy fiber synapses (Weisskopf et al., 1994). Miniature non-NMDAR-mediated EPSCs were recorded in the presence of TTX $(1 \mu \mathrm{M})$, bicuculline $(10 \mu \mathrm{M})$, and D-APV $(40 \mu \mathrm{M})$. Bath application of FSK $(10 \mu \mathrm{M})$ induced a gradual and long-lasting increase in the frequency of mEPSCs to $380 \pm 59 \%$ of control (Fig. $6 A, B$ ) (paired $t$ test; $p=0.016 ; n=5$ ) without significant change in amplitude (see Fig. $6 D$ for the distribution) $(116 \pm 18 \%$ of control; paired $t$ test; $p=0.508 ; n=5)$. The frequency analysis of $\mathrm{mEPSC}_{\mathrm{KA}}$ and $\mathrm{mEPSC}_{\mathrm{AMPA}}$ using our kinetic limits showed that both were significantly enhanced $20 \mathrm{~min}$ after FSK application (Fig. 6A,C) (to $433 \pm 75 \%$ of control, paired $t$ test, $p=0.035$ for mEPSC $_{\mathrm{KA}}$; to $350 \pm 48 \%$ of control, paired $t$ test, $p=0.009$ for $\mathrm{mEPSC}_{\mathrm{AMPA}} ; n=5$ for each). Thus, mEPSC $_{\mathrm{KA}} \mathrm{s}$ are highly sensitive to FSK application, and this further supports the mossy fiber origin of these events. These results also suggest that mossy fibers generate $\mathrm{EPSC}_{\mathrm{AMPA}}$, as reported previously (Okazaki and Nadler, 2001).

To confirm that recurrent mossy fibers generated $\mathrm{EPSC}_{\mathrm{AMPA}}$ in addition to $\mathrm{EPSC}_{\mathrm{KA}}$, we selectively stimulated dentate GCs using focal pressure application of the nonhydrolysable glutamate agonist KA to the molecular layer while recording from a distant GC (Fig. 7A) (Wuarin and Dudek, 1996). Methylene blue was routinely added to the agonist solution to visualize the flow during pressure application and evaluate the spatial extent of the stimulation. Distribution of the ink typically indicated a diffusion of $\sim 150 \mu \mathrm{M}$ from the tip of the pipette. We also used a high divalent cation-containing medium $\left(\mathrm{Ca}^{2+} 8 \mathrm{~mm}\right)$, which blocked polysynaptic activities (Berry and Pentreath, 1976), to avoid unspecific spread of activity. Pressure application of KA ( $30 \mu \mathrm{M} ; 20-50 \mathrm{~ms}$ duration) directly on the recorded GC in the presence of D-APV $(40 \mu \mathrm{M})$ and bicuculline $(10 \mu \mathrm{M})$ generated an inward current that lasted for several seconds (typically $\sim 60 \mathrm{~s}$ ) (Fig. $7 A$ ). Focal applications of KA with a micropipette placed in the molecular layer of the dentate gyrus from a pilocarpine-treated rat, but at a distance of $\geq 300 \mu \mathrm{m}$ from the recorded cell, increased the frequency of EPSCs (in 7 of 28 GCs) without underlying current (Fig. $7 B)$. This effect lasted between 30 and $60 \mathrm{~s}$ (i.e., in the same range as the current evoked when applying KA directly on the recorded cell) (Fig. 7A). The frequency analysis of EPSC $_{\mathrm{AMPA}}$ and $\mathrm{EPSC}_{\mathrm{KA}}$ showed that both were significantly enhanced (Fig. 7C,D) (to $264 \pm 58 \%$ of control, paired $t$ test, $p=0.04$ for EPSC $_{\mathrm{AMPA}}$; to $244 \pm 35 \%$ of control, paired $t$ test, $p=$ 0.004 for $\mathrm{EPSC}_{\mathrm{KA}} ; n=7$ for each). Similar stimulations in the molecular layer of the dentate gyrus from control rats failed to change the frequency of EPSCs in distant recorded dentate GCs $(n=20$; data not shown) as described previously (Wuarin and Dudek, 1996). Therefore, the recurrent mossy fibers generated $\mathrm{EPSC}_{\mathrm{AMPA}}$ in addition to $\mathrm{EPSC}_{\mathrm{KA}}$ in dentate granule cells from epileptic rats.

To test the specificity of these responses, we determined whether spontaneous $\mathrm{EPSC}_{\mathrm{KA}} \mathrm{s}$ could also be generated by mossy cells that may survive the pilocarpineinduced status epilepticus (Scharfman et al., 2001). Using an antibody against GluR2/3 to label mossy cells in the hilar region (Leranth et al., 1996), we found that some glutamatergic hilar mossy cells survived the status epilepticus (33-47\%) (supplemental Fig. S2 A, available at www.jneurosci.org as supplemental material) as described previously (Scharfman et al., 2001). Using the same focal stimulation protocol in the hilus (supplemental Fig. S2 B, available at www.jneurosci.org as supplemental material), we observed an increase in the frequency of EPSCs in GCs ( $n=7$ of 15) (supplemental Fig. S2C, available at www.jneurosci. org as supplemental material) during 30-60 s. However, only EPSC $_{\text {AMPA }}$ frequency was significantly increased (to $533 \pm 211 \%$ of control; $n=7$; paired $t$ test; $p=0.024)$; the frequency of EPSC $_{\mathrm{KA}}$ was not changed (107 $\pm 23 \%$ of control; $n=7$; paired $t$ test; $p=0.855$ ) (supplemental Fig. S2 D, E, available at www. jneurosci.org as supplemental material). As expected, in control hippocampal slices, similar stimulations in the hilus enhanced the frequency of EPSC $_{\mathrm{AMPA}}$ to $439 \pm 136 \%$ of control $(n=3$ of 4 GCs) (data not shown).

Altogether, these experiments showed that recurrent mossy fibers generate both $\mathrm{EPSC}_{\mathrm{KA}} \mathrm{s}$ and $\mathrm{EPSC}_{\mathrm{AMPA}} \mathrm{s}$ in dentate granule cells from pilocarpine-treated rats. 


\section{Epileptic Rat}

A

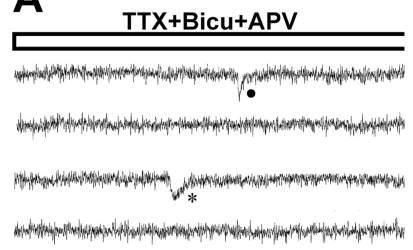

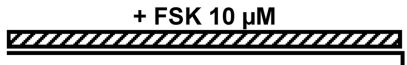
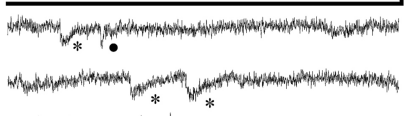

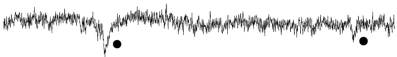
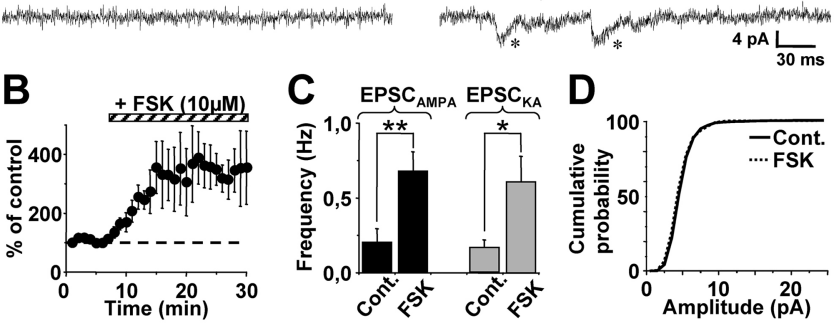

Figure 6. FSK induces a long-lasting enhancement of the frequency of $\mathrm{mEPSC}_{\mathrm{KA}}$ and $\mathrm{mEPSC}_{\mathrm{AMPA}}$ in granule cells from epileptic rats. $A$, mEPSC recordings in the presence of $1 \mu \mathrm{M}$ TTX, $10 \mu \mathrm{m}$ bicuculline (Bicu), and $40 \mu \mathrm{m}$ D-APV in a granule cell from an epileptic rat in the absence (left) and $20 \mathrm{~min}$ after the application of $10 \mu \mathrm{m} \mathrm{FSK} \mathrm{(right).} \mathrm{Note} \mathrm{that} \mathrm{in} \mathrm{the} \mathrm{presence} \mathrm{of} \mathrm{FSK,} \mathrm{the}$ frequency of both $m E P S C_{A M P A}$ (filled circle) and ${ } E P S C_{K A}$ (asterisk) is increased. $\boldsymbol{B}$, Time course of the FSK effect on the mean frequency of miniature events $(n=5)$. C, Bar graphs of the mean frequency of $\mathrm{mEPSC}_{\mathrm{AMPA}}$ and $\mathrm{mEPSC} \mathrm{KA}_{\mathrm{KA}}$ recorded before (Cont.) and $20 \mathrm{~min}$ after the application of FSK. The frequency of $m E P S C_{K A}$ and $m E P S C_{A M P A}$ is significantly increased $\left(n=5\right.$; ${ }^{*} p<0.05$; ${ }^{* *} p<0.01$ ). D, Cumulative probability plots of amplitudes of miniature EPSCs before (solid line) and 20 min after (dotted line) FSK application. Note that there is no significant difference in the amplitudes of mEPSCs before and $20 \mathrm{~min}$ after FSK application.

Blockade of kainate receptors reduces synchronized networkdriven activities in the dentate gyrus from epileptic rats Because mossy fiber sprouting leads to the formation of a recurrent excitatory circuit between GCs in epileptic rats (Tauck and Nadler, 1985; Wuarin and Dudek, 1996; Molnar and Nadler, 1999; Buckmaster et al., 2002; Scharfman et al., 2003) that support synchronized burst discharges (Patrylo and Dudek, 1998; Hardison et al., 2000; Okazaki and Nadler, 2001), we then determined whether blockade of KARs could reduce recurrent mossy fiber network-driven activities. To test this hypothesis, synchronized burst discharges were evoked by antidromic stimulation of the mossy fiber pathway in the CA3b area in high potassium containing ASCF $(6 \mathrm{~mm})$ in the continuous presence of bicuculline (Fig. 8A) (10 $\mu \mathrm{M})$ (Patrylo and Dudek, 1998; Hardison et al., 2000) while recording local field potentials in the dentate granular layer. In these conditions, we were able to evoke burst activities in 9 of 10 slices from epileptic rats but in none of the nine control slices tested (Fig. $8 \mathrm{~B}$ ). We used the coastline burst index to quantify the involvement of KARs in burst discharges (Dingledine et al., 1986). Desensitization of KARs using SYM 2081 (10 $\mu \mathrm{M})$ significantly reduced the coastline burst index in eight of nine tested slices to $56.8 \pm 4.58 \%$ of control condition (Fig. $8 B$ ) ( $n=682$ bursts; Wilcoxon; $p=0.008$ ) without affecting the initial population spike ( $100 \pm 6.08 \%$ of control; $n=9$; Wilcoxon; $p=0.82)$. Thus, KARs are involved in synchronized network-driven activities supported by recurrent mossy fibers in the dentate gyrus from epileptic rats.

\section{Discussion}

The main result of this study is that mossy fiber sprouting in epilepsies induces the formation of functional aberrant synapses on GCs of the dentate gyrus that are endowed with an important KAR-mediated synaptic component absent in control cells. Indeed, whereas control GCs have only a fast $\mathrm{EPSC}_{\mathrm{AMPA}}$, GCs from

\section{Epileptic Rat}

A
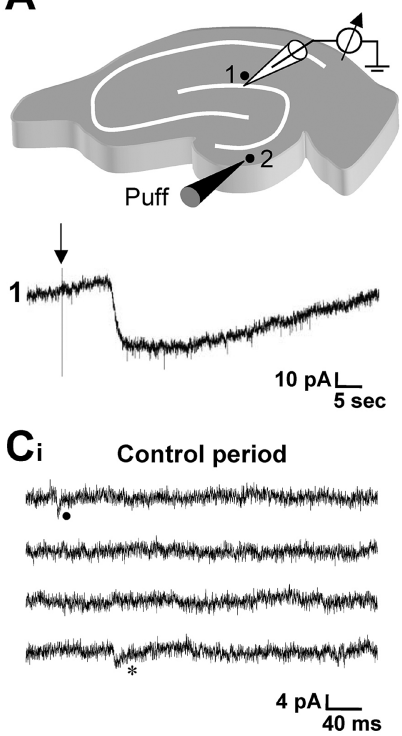

$\mathbf{C}_{\text {iii }}$

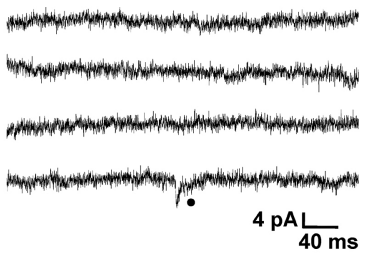

B
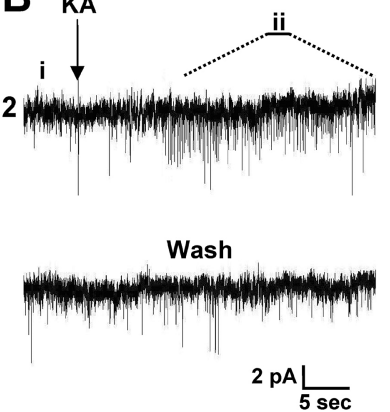

$\mathbf{C}_{\mathrm{ii}} \quad$ Stimulation

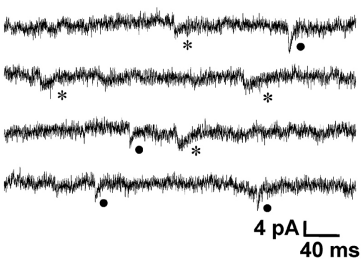

D

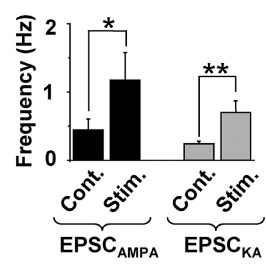

Figure 7. Focal stimulation in the dentate gyrus evokes both AMPA and kainate receptormediated EPSCs in granule cells from epileptic rats. $A$, Drawing of a hippocampal slice depicting the position of the recording pipette and the locus for focal application (puff; $50 \mathrm{~ms}$ duration) of $30 \mu \mathrm{m}$ kainate (KA; top). Focal application of kainate on the recorded dentate granule cell (1) induces a long- lasting inward current (bottom). B, Puff application of KA (arrow) induces an increase in the frequency of spontaneous EPSCs in a distant recorded granule cell. $C$, Enlargement of the recording shown in $\boldsymbol{B}$ enables the identification of spontaneous EPSC $_{\text {AMPA }}$ (filled circle) and EPSC $\mathrm{KA}_{\mathrm{KA}}$ (asterisk) before $\left(\boldsymbol{C}_{\boldsymbol{i}}\right.$, Control period) and after ( $\boldsymbol{C}_{i j}$, Stimulation) the distant application of kainate. The frequency of both EPSC $C_{A M P A}$ and $E P S C_{K A}$ is increased. This effect is reversible ( $\boldsymbol{C}_{i i i}$,Wash). Traces are consecutives in $\boldsymbol{C}_{i}, \boldsymbol{C}_{i i}$, and $\boldsymbol{C}_{i i i}$ and correspond to the i, ii, and wash periods indicated in $\boldsymbol{B}$. $\boldsymbol{D}$, Bar graphs of the mean frequency of spontaneous EPSC $_{\mathrm{AMPA}}$ and $E P S C_{K A}$ recorded before (Cont.) and during (Stim.) the stimulation period (60 s). The frequency of both EPSC $\mathrm{AMPA}_{\text {and }}$ aPSC $\mathrm{KA}_{\mathrm{KA}}$ is significantly increased ( $n=7$ stimulations in 7 cells; ${ }^{*} p<0.05$; $\left.{ }^{* *} p<0.01\right)$.

epileptic rats have, in addition to fast $\mathrm{EPSC}_{\mathrm{AMPA}}$, slower $\mathrm{EPSC}_{\mathrm{KA}}$ that provide as much as half of the total spontaneous synaptic glutamatergic currents. This is, to the best of our knowledge, the first demonstration of formation of novel KAR-operated synapses on aberrant targets in pathological conditions.

\section{Mossy fiber origin of EPSC $_{\mathrm{KA}}$}

In the control hippocampus, mossy fiber synapses display both presynaptic- and postsynaptic-specific features (Henze et al., 2000). On the presynaptic side, these synapses are downregulated by the activation of mGluR2/3 receptors (Kamiya et al., 1996) and present a specific form of frequency facilitation (Salin et al., 1996) via the activation of presynaptic KARs (Schmitz et al., 2001); on the postsynaptic side, mossy fiber synapses onto CA3 pyramidal cells selectively generate EPSC $_{\mathrm{KA}}$ (Castillo et al., 1997; Cossart et al., 2002). Previous studies have shown that presynaptic features of mossy fibers are preserved after sprouting in the epileptic hippocampus (Feng et al., 2003). We now report that, in addition to 

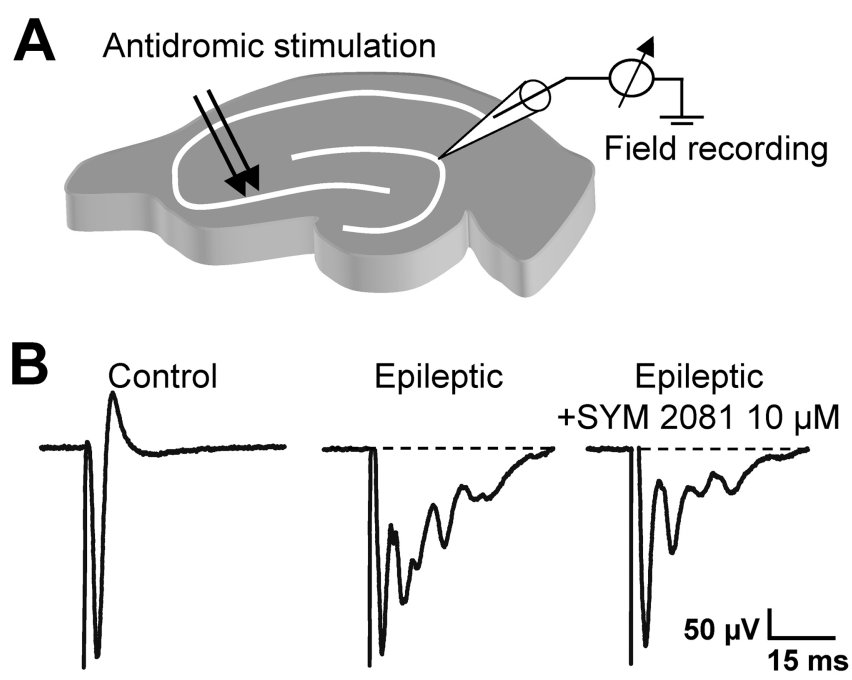

Figure 8. Desensitization of kainate receptors reduces synchronized burst discharges in granule cells from epileptic rats. $A$, Drawing of a hippocampal slice depicting the position of the extracellular recording pipette (granule cell layer) and the stimulating electrode (arrows, lucidum of CA3b to antidromically stimulate granule cells). Experiments were performed in $6 \mathrm{~mm}$ $\mathrm{K}^{+}$containing ACSF and $10 \mu \mathrm{m}$ bicuculline. $\boldsymbol{B}$, Digitally averaged traces showing that antidromic stimulations of mossy fibers evoke a single population spike (61 averaged traces, left) in a control slice, and a population spike followed by an interictal burst discharge (67 averaged traces; middle) in a slice from an epileptic rat. Note that bath application of $10 \mu \mathrm{m}$ SYM 2081 (which desensitizes KARs) reduces the severity of the burst discharge in the epileptic slice (as shown by 67 averaged traces; right).

these presynaptic features, recurrent mossy fibers also conserve their postsynaptic specificity, because they generate EPSC $_{\mathrm{KA}}:(1)$ EPSC $_{\mathrm{KA}}$ are recorded in chronic epileptic rats that showed strong mossy fiber sprouting but not in control or 4- to 5-d-poststatus epilepticus rats that showed no mossy fiber sprouting; (2) in chronic epileptic rats, EPSC $_{\mathrm{KA}}$ can be evoked by minimal stimulation in the inner molecular layer of the dentate gyrus, the terminal zone of recurrent mossy fibers; (3) these unitary $\mathrm{EPSC}_{\mathrm{KA}} \mathrm{s}$ show pharmacological and physiological features specific of mossy fiber synapses such as sensitivity to DCGIV and forskolin and frequency-dependent facilitation; (4) EPSC $_{\mathrm{KA}}$ can be generated by the focal stimulation of distant GCs but not hilar mossy cells; and (5) blockade of KARs reduce recurrent mossy fiber network-driven activities. These results suggest that the establishment of new KAR-operated synapses in GCs from epileptic rats is triggered by the arrival of mossy fiber axons as shown previously for CA3 pyramidal cells during development (Marchal and Mulle, 2004). This reinforces and extends the unique relationship between mossy fibers and KAR-operated synapses (Monaghan and Cotman, 1982; Represa et al., 1987; Castillo et al., 1997; Vignes and Collingridge, 1997; Mulle et al., 1998; Cossart et al., 2002; Marchal and Mulle, 2004). Postsynaptic KARs, unlike the widespread expression of postsynaptic AMPARs, are expressed in specific cell types (Huettner, 2003; Lerma, 2003). Among principal cells of the control hippocampus, only CA3 pyramidal cells use KARs as postsynaptic mediators of ionotropic glutamatergic transmission (Lerma, 2003). Additionally, our results show that mossy fiber sprouting induces a reorganization of KAR-mediated synaptic transmission in the hippocampus of chronic epileptic rats.

\section{Properties of aberrant EPSC $_{\mathrm{KA}}$}

The $\mathrm{EPSC}_{\mathrm{KA}} \mathrm{s}$ generated in GCs in chronic epileptic rats share common physiological features with EPSC $_{\mathrm{KA}}$ described in CA3 pyramidal cells and CA1 interneurons in the control hippocampus (Cossart et al., 2002). KARs in GCs from epileptic rats can be activated by the quantal release of glutamate, because we were able to pharmacologically isolate miniature $\mathrm{EPSC}_{\mathrm{KA}}$ and to minimally evoke these events. These unitary events display a slow time course and a small amplitude when compared with EPSC $_{\text {AMPA }}$ (Castillo et al., 1997; Vignes and Collingridge, 1997; Frerking et al., 1998; Cossart et al., 2002). Their slow time course is most likely attributable to intrinsic features of KARs as observed in other systems (Lerma, 2003) and not to changes of intrinsic membrane properties of GCs after epilepsy. Accord-

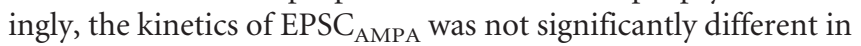
epileptic and control GCs. Furthermore, we show that focal GC stimulations or minimal stimulations of recurrent mossy fibers evoked either slow KAR- or fast AMPAR-mediated EPSCs but not mixed AMPAR/KAR-mediated EPSCs. These observations suggest that, in epileptic GCs, AMPARs and KARs are likely to be clustered into different mossy fiber synapses in contrast to control CA3 pyramidal cells in which most KARs are colocalized with AMPARs (Cossart et al., 2002).

\section{Implications for temporal lobe epilepsy}

Previous studies emphasized the role of KARs in epileptiform activities induced by acute administration of convulsing agents in vitro or in vivo (Ben-Ari, 1985; Gaiarsa et al., 1994; Mulle et al., 1998; Ben-Ari and Cossart, 2000; Smolders et al., 2002; Rogawski et al., 2003) and in particular the effects of kainate administration that trigger a seizure and brain damage syndrome that mimics human TLE (BenAri, 1985). In the present study, we were concerned by the fate of KAR-mediated synaptic transmission in chronic epileptic rats that developed spontaneous behavioral seizures. In animal models and in patients with TLE, mossy fiber sprouting leads to the formation of a functional recurrent excitatory circuit between granule cells (Tauck and Nadler, 1985; Wuarin and Dudek, 1996; Molnar and Nadler, 1999; Buckmaster et al., 2002; Scharfman et al., 2003) that support epileptiform bursts (Patrylo and Dudek, 1998; Hardison et al., 2000; Gabriel et al., 2004). Mossy fiber sprouting occurs as a compensatory mechanism to the death of hilar mossy cells and the resulting loss of glutamatergic inputs in the inner molecular layer of the dentate gyrus. Our results show that the overall frequency of mEPSCs in GCs is not significantly different between control and chronic epileptic animals, suggesting that mossy fiber sprouting quantitatively compensates for the loss of glutamatergic excitatory inputs. Despite this quantitative compensation, we found a profound change between GCs from control and chronic epileptic rats, because only the latter use KARs as postsynaptic mediators of ionotropic glutamatergic synaptic transmission. What could be the functional consequences of this change? Because $\mathrm{EPSC}_{\mathrm{KA}}$ from recurrent mossy fibers represent half of the glutamatergic currents, activation of KARs in addition to AMPARs (Okazaki et al., 2001) should contribute to the epileptiform bursts supported by the recurrent mossy fiber network. Although additional studies are required to substantiate this, the inhibitory effect of a selective KAR blocker on synchronized activities generated by the recurrent mossy fiber network is in keeping with this hypothesis. These observations, together with previous studies, are compatible with an anti-epileptic strategy based on kainate receptor antagonists. Furthermore, the present observations show that the functional consequences of reactive plasticity on glutamatergic synaptic transmission should not only be evaluated in terms of quantitative changes but also qualitative changes. Indeed, whereas control GCs of the dentate gyrus have only fast 
$\mathrm{EPSC}_{\mathrm{AMPA}}$, GCs from epileptic rats have fast $\mathrm{EPSC}_{\mathrm{AMPA}}$ and slower EPSC $_{\mathrm{KA}}$. Computing studies have shown that $\mathrm{EPSC}_{\mathrm{AMPA}}$ and $\mathrm{EPSC}_{\mathrm{KA}}$ encode different features of afferent activity (Frerking and Ohligre-Frerking, 2002): $\mathrm{EPSC}_{\mathrm{KA}} \mathrm{s}$, with slow kinetics, generate a large tonic depolarization when activated by afferent inputs, whereas $\mathrm{EPSC}_{\mathrm{AMPA}} \mathrm{s}$ conserve the temporal structure of the signal. Thus, the activation of both AMPARs and KARs at recurrent mossy fiber synapses would greatly modify the computational properties of these cells.

In conclusion, we show that, in addition to axonal rewiring, mossy fiber sprouting induces a reorganization of KAR-mediated synaptic transmission in the hippocampus from chronic epileptic rats together with a shift in the nature of glutamatergic transmission in GCs. This, together with other alterations that occur in the hippocampus (Nadler, 2003), might be important for the pathogenesis of temporal lobe epilepsy.

\section{References}

Ascher P, Nowak L (1988) The role of divalent-cations in the N-methyl-Daspartate responses of mouse central neurons in culture. J Physiol (Lond) 399:247-266.

Ben-Ari Y (1985) Limbic seizure and brain-damage produced by kainic acid-mechanisms and relevance to human temporal-lobe epilepsy. Neuroscience 14:375-403.

Ben-Ari Y, Cossart R (2000) Kainate, a double agent that generates seizures: two decades of progress. Trends Neurosci 23:580-587.

Ben-Ari Y, Represa A (1990) Brief seizure episodes induce long-term potentiation and mossy fiber sprouting in the hippocampus. Trends Neurosci 13:312-318.

Berry MS, Pentreath VW (1976) Criteria for distinguishing between monosynaptic and polysynaptic transmission. Brain Res 105:1-20.

Buckmaster PS, Dudek FE (1999) In vivo intracellular analysis of granule cell axon reorganization in epileptic rats. J Neurophysiol 81:712-721.

Buckmaster PS, Zhang GF, Yamawaki R (2002) Axon sprouting in a model of temporal lobe epilepsy creates a predominantly excitatory feedback circuit. J Neurosci 22:6650-6658.

Bureau I, Bischoff S, Heinemann SF, Mulle C (1999) Kainate receptormediated responses in the CA1 field of wild-type and GluR6-deficient mice. J Neurosci 19:653-663.

Castillo PE, Malenka RC, Nicoll RA (1997) Kainate receptors mediate a slow postsynaptic current in hippocampal CA3 neurons. Nature 388:182-186.

Cossart R, Esclapez M, Hirsch JC, Bernard C, Ben Ari Y (1998) GluR5 kainate receptor activation in interneurons increases tonic inhibition of pyramidal cells. Nat Neurosci 1:470-478.

Cossart R, Epsztein J, Tyzio R, Becq H, Hirsch J, Ben Ari Y, Crepel V (2002) Quantal release of glutamate generates pure kainate and mixed AMPA/ kainate EPSCs in hippocampal neurons. Neuron 35:147-159.

DeVries SH, Schwartz EA (1999) Kainate receptors mediate synaptic transmission between cones and "off" bipolar cells in a mammalian retina. Nature 397:157-160.

Dingledine R, Hynes MA, King GL (1986) Involvement of N-methyl-Daspartate receptors in epileptiform bursting in the rat hippocampal slice. J Physiol (Lond) 380:175-189.

Feng L, Molnar P, Nadler JV (2003) Short-term frequency-dependent plasticity at recurrent mossy fiber synapses of the epileptic brain. J Neurosci 23:5381-5390.

Franck JE, Pokorny J, Kunkel DD, Schwartzkroin PA (1995) Physiological and morphologic characteristics of granule cell circuitry in human epileptic hippocampus. Epilepsia 36:543-558.

Fremeau J, Voglmaier S, Seal RP, Edwards RH (2004) VGLUTs define subsets of excitatory neurons and suggest novel roles for glutamate. Trends Neurosci 27:98-103.

Frerking M, Nicoll RA (2000) Synaptic kainate receptors. Curr Opin Neurobiol 10:342-351.

Frerking M, Ohligre-Frerking P (2002) AMPA receptors and kainate receptors encode different features of afferent activity. J Neurosci 22:7434-7443.

Frerking M, Malenka RC, Nicoll RA (1998) Synaptic activation of kainate receptors on hippocampal interneurons. Nat Neurosci 1:479-486.

Gabriel S, Njunting M, Pomper JK, Merschhemke M, Sanabria ER, Eilers A,
Kivi A, Zeller M, Meencke HJ, Cavalheiro EA, Heinemann U, Lehmann TN (2004) Stimulus and potassium-induced epileptiform activity in the human dentate gyrus from patients with and without hippocampal sclerosis. J Neurosci 24:10416-10430.

Gaiarsa JL, Zagrean L, Ben Ari Y (1994) Neonatal irradiation prevents the formation of hippocampal mossy fibers and the epileptic action of kainate on rat CA3 pyramidal neurons. J Neurophysiol 71:204-215.

Hardison JL, Okazaki MM, Nadler JV (2000) Modest increase in extracellular potassium unmasks effect of recurrent mossy fiber growth. J Neurophysiol 84:2380-2389.

Henze DA, Urban NN, Barrionuevo G (2000) The multifarious hippocampal mossy fiber pathway: a review. Neuroscience 98:407-427.

Huettner JE (2003) Kainate receptors and synaptic transmission. Prog Neurobiol 70:387-407.

Isokawa M, Levesque MF, Babb TL, Engel J (1993) Single mossy fiber axonal systems of human dentate granule cells studied in hippocampal slices from patients with temporal-lobe epilepsy. J Neurosci 13:1511-1522.

Kamiya H, Shinozaki H, Yamamoto C (1996) Activation of metabotropic glutamate receptor type 2/3 suppresses transmission at rat hippocampal mossy fibre synapses. J Physiol (Lond) 493:447-455.

Leranth C, Szeidemann Z, Hsu M, Buzsaki G (1996) AMPA receptors in the rat and primate hippocampus: a possible absence of GLUR2/3 subunits in most interneurons. Neuroscience 70:631-652.

Lerma J (2003) Roles and rules of kainate receptors in synaptic transmission. Nat Rev Neurosci 4:481-495.

Li H, Rogawski MA (1998) GluR5 kainate receptor mediated synaptic transmission in rat basolateral amygdala in vitro. Neuropharmacology 37:1279-1286.

Li P, Wilding TJ, Kim SJ, Calejesan AA, Huettner JE, Zhuo M (1999) Kainate-receptor-mediated sensory synaptic transmission in mammalian spinal cord. Nature 397:161-164.

Lynch M, Sutula T (2000) Recurrent excitatory connectivity in the dentate gyrus of kindled and kainic acid-treated rats. J Neurophysiol 83:693-704.

Marchal C, Mulle C (2004) Postnatal maturation of mossy fibre excitatory transmission in mouse CA3 pyramidal cells: a potential role for kainate receptors. J Physiol (Lond) 561:27-37.

Mello LE, Cavalheiro EA, Tan AM, Kupfer WR, Pretorius JK, Babb TL, Finch DM (1993) Circuit mechanisms of seizures in the pilocarpine model of chronic epilepsy: cell loss and mossy fiber sprouting. Epilepsia 34:985-995.

Molnar P, Nadler JV (1999) Mossy fiber-granule cell synapses in the normal and epileptic rat dentate gyrus studied with minimal laser photostimulation. J Neurophysiol 82:1883-1894.

Monaghan DT, Cotman CW (1982) The distribution of [3H]kainic acid binding sites in rat CNS as determined by autoradiography. Brain Res 252:91-100.

Mulle C, Sailer A, Perez-Otano I, Dickinson-Anson H, Castillo PE, Bureau I, Maron C, Gage FH, Mann JR, Bettler B, Heinemann SF (1998) Altered synaptic physiology and reduced susceptibility to kainate-induced seizures in GluR6-deficient mice. Nature 392:601-605.

Nadler JV (2003) The recurrent mossy fiber pathway of the epileptic brain. Neurochemical Res 28:1649-1658.

Okazaki MM, Nadler JV (2001) Glutamate receptor involvement in dentate granule cell epileptiform activity evoked by mossy fiber stimulation. Brain Res 915:58-69.

Okazaki MM, Evenson DA, Nadler JV (1995) Hippocampal mossy fiber sprouting and synapse formation after status epilepticus in rats-visualization after retrograde transport of biocytin. J Comp Neurol 352:515-534.

Patrylo PR, Dudek FE (1998) Physiological unmasking of new glutamatergic pathways in the dentate gyrus of hippocampal slices from kainateinduced epileptic rats. J Neurophysiol 79:418-429.

Racine RJ (1972) Modification of seizure activity by electrical stimulation. II. Motor seizure. Electroencephalogr Clin Neurophysiol 32:281-294.

Represa A, Tremblay E, Ben Ari Y (1987) Kainate binding-sites in the hippocampal mossy fibers-localization and plasticity. Neuroscience 20:739-748.

Represa A, Robain O, Tremblay E, Ben Ari Y (1989) Hippocampal plasticity in childhood epilepsy. Neurosci Lett 99:351-355.

Represa A, Jorquera I, Lasalle GL, Ben Ari Y (1993) Epilepsy induced collateral sprouting of hippocampal mossy fibers-does it induce the development of ectopic synapses with granule cell dendrites. Hippocampus 3:257-268. 
Rogawski MA, Gryder D, Castaneda D, Yonekawa W, Banks MK, Lia H (2003) GluR5 kainate receptors, seizures, and the amygdala. Ann NY Acad Sci 985:150-162.

Salin PA, Scanziani M, Malenka RC, Nicoll RA (1996) Distinct short-term plasticity at two excitatory synapses in the hippocampus. Proc Natl Acad Sci USA 93:13304-13309.

Scharfman HE, Smith KL, Goodman JH, Sollas AL (2001) Survival of dentate hilar mossy cells after pilocarpine-induced seizures and their synchronized burst discharges with area CA3 pyramidal cells. Neuroscience 104:741-759.

Scharfman HE, Sollas AL, Berger RE, Goodman JH (2003) Electrophysiological evidence of monosynaptic excitatory transmission between granule cells after seizure-induced mossy fiber sprouting. J Neurophysiol 90:2536-2547.

Schmitz D, Mellor J, Nicoll RA (2001) Presynaptic kainate receptor mediation of frequency facilitation at hippocampal mossy fiber synapses. Science 291:1972-1976.

Smolders I, Bortolotto ZA, Clarke VR, Warre R, Khan GM, O’Neill MJ, Ornstein PL, Bleakman D, Ogden A, Weiss B, Stables JP, Ho KH, Ebinger G, Collingridge GL, Lodge D, Michotte Y (2002) Antagonists of GLU(K5)containing kainate receptors prevent pilocarpine-induced limbic seizures. Nat Neurosci 5:796-804.
Sutula T, He XX, Cavazos J, Scott G (1988) Synaptic reorganization in the hippocampus induced by abnormal functional-activity. Science 239:1147-1150.

Sutula T, Cascino G, Cavazos J, Parada I, Ramirez L (1989) Mossy fiber synaptic reorganization in the epileptic human temporal-lobe. Ann Neurol 26:321-330.

Tauck DL, Nadler JV (1985) Evidence of functional mossy fiber sprouting in hippocampal-formation of kainic acid-treated rats. J Neurosci 5:1016-1022.

Vignes M, Collingridge GL (1997) The synaptic activation of kainate receptors. Nature 388:179-182.

Weisskopf MG, Castillo PE, Zalutsky RA, Nicoll RA (1994) Mediation of hippocampal mossy fiber long-term potentiation by cyclic-AMP. Science 265:1878-1882.

Wuarin JP, Dudek FE (1996) Electrographic seizures and new recurrent excitatory circuits in the dentate gyrus of hippocampal slices from kainatetreated epileptic rats. J Neurosci 16:4438-4448.

Wuarin JP, Dudek FE (2001) Excitatory synaptic input to granule cells increases with time after kainate treatment. J Neurophysiol 85: 1067-1077. 